\title{
REFINAMENTO GEOMÉTRICO DE CONTORNOS E CUMEEIRAS DE TELHADOS DE EDIFÍCIOS EXTRAÍDOS DE DADOS LASER COM USO DE IMAGEM AÉREA
}

\begin{abstract}
Geometric refinement of laser-derived building roof contours and ridges using aerial image
\end{abstract}

\author{
VANESSA JORDÃO MARCATO \\ ALUIR PORFIRIO DAL POZ
}

\author{
Programa de Pós-graduação em Ciências Cartográficas \\ Faculdade de Ciências e Tecnologia - Departamento de Cartografia \\ UNESP - Universidade Estadual Paulista \\ Rua Roberto Simonsen, 305 \\ 19060-900 - Presidente Prudente - SP - Brasil \\ vanessamarcato@yahoo.com.br, aluir@fct.unesp.br
}

\begin{abstract}
RESUMO
Nesse artigo é proposto um método para refinar geometricamente telhados 3D extraídos dos dados LASER com o uso de uma imagem aérea de alta-resolução e modelos de campo aleatório de Markov (MRF - Markov Random Field). Para tanto, uma descrição MRF para agrupamento de retas é desenvolvida, assumindo que cada lado de contorno e cumeeira projetado está topologicamente correto e que é necessário apenas melhorar sua acurácia. Embora a combinação de dados LASER com dados de imagem é justificada mais para o refinamento de contorno de telhado, a estrutura de cumeeiras pode dar maior robustez na descrição topológica da estrutura de telhado. O modelo MRF é formulado com base em relações (de comprimento, proximidade e orientação) entre as retas extraídas da imagem e o polígono projetado e, também, em injunções de retangularidade e quina. A função de energia associada à descrição MRF é minimizada via algoritmo genético, resultando em um agrupamento de retas para cada telhado. Finalmente, o agrupamento de retas é topologicamente reconstruído baseando-se na topologia do correspondente polígono projetado no espaço imagem. Os resultados obtidos foram satisfatórios. Esse método foi capaz de fornecer polígonos de telhado refinados em
\end{abstract}


que a maioria de seus lados de contorno e cumeeira foram geometricamente melhorados.

Palavras-chave: Extração de Edifícios; Dados LASER; Imagens Aéreas; MRF.

\section{ABSTRACT}

In this paper, a method is proposed to refine the LASER 3D roofs geometrically by using a high-resolution aerial image and Markov Random Field (MRF) models. In order to do so, a MRF description for grouping straight lines is developed, assuming that each projected side contour and ridge is topologically correct and that it is only necessary to improve its accuracy. Although the combination of laser data with data from image is most justified for refining roof contour, the structure of ridges can give greater robustness in the topological description of the roof structure. The MRF model is formulated based on relationships (length, proximity, and orientation) between the straight lines extracted from the image and projected polygon and also on retangularity and corner injunctions. The energy function associated with MRF is minimized by the genetic algorithm optimization method, resulting in the grouping of straight lines for each roof object. Finally, each grouping of straight lines is topologically reconstructed based on the topology of the corresponding LASER scanning polygon projected onto the image-space. The results obtained were satisfactory. This method was able to provide polygons roof refined buildings in which most of its contour sides and ridges were geometrically improved.

Keywords: Building Extraction; LASER Data; Aerial Image; MRF.

\section{INTRODUÇÃO}

As pesquisas na área de extração de feições têm crescido nos últimos anos. Em particular, a extração de telhados de edifícios tem sido estudada por mais de três décadas. Até meados da década de 1990 as imagens aéreas eram as fontes usuais de dados utilizadas para a extração. No final dessa mesma década outras fontes de dados (por exemplo, as imagens de satélites de alta-resolução e os dados de varredura a LASER) passaram a ser utilizadas. O uso de dados LASER em problemas de extração se tornou comum nos últimos anos. O desenvolvimento de metodologias que utilizam esse tipo de dados para mapeamento é bastante atrativo às aplicações que envolvem a reconstrução e extração de objetos, procurando a solução de problemas específicos envolvendo, por exemplo, a segmentação e a filtragem de objetos (edifícios, vegetação etc.) para a geração de MDT (Modelo Digital de Terreno) e MDS (Modelo Digital de Superfície). Em Vosselman (1999) a proposta básica é extrair planos de telhados e combiná-los para extrair por intersecção as cumeeiras. Já os contornos são detectados e delineados por meio de algoritmos de detecção de descontinuidade. Rottensteiner et al. (2005) e Botelho e Centeno (2007) adotam, de um modo geral, os mesmos princípios. Já Lafarge et al. (2008) desenvolveram uma metodologia para a extração de edifícios a partir de Modelos Digitais de Superfície (MDS), em que as partes dos edifícios são extraídas 
como objetos retangulares. Estes objetos são posteriormente agregados para gerar modelos 3D completos de edificações. Uma metodologia específica para extração de contornos de telhados a partir de um MDS é proposta em Galvanin e Dal Poz (2012). Primeiramente, a fim de detectar objetos altos (edifícios altos, árvores etc.), o MDS é segmentado via divisão recursiva e fusão por inferência bayesiana. A extração dos contornos de telhados é focada nos objetos altos detectados, cujo problema é formulado e resolvido com base na teoria dos campos aleatórios de Markov (MRF - Markov Random Field). A extração de telhados de edifícios é um problema difícil no âmbito do reconhecimento de objetos, o que está relacionado com a complexidade e a variabilidade da cena e, dessa forma, para minimizar esse problema se torna interessante o desenvolvimento de metodologias que utilizam várias fontes de dados (SOHN, 2004). O problema de extração de edifícios com o uso de dados LASER conjuntamente com dados de imagem vem sendo investigado nos últimos anos. Essa combinação de dados é atrativa para esse problema, uma vez que esses dois dados possuem informações complementares Dal Poz et al. (2009a).

Várias metodologias dessa classe podem ser encontradas na literatura. Haala e Brenner (1999) combinaram imagens multiespectrais e dados MDS/LASER (Modelo Digital de Superfície gerado a partir de dados LASER) para separar edifícios de vegetação. Sohn e Dowman (2003) sugeriram outra metodologia, em que inicialmente os edifícios são extraídos separadamente de uma imagem Ikonos e de dados MDS/LASER e, em seguida, ambos os resultados são combinados para a remoção de inconsistências. Machado e Mitishita (2006) combinaram imagens aéreas de pequeno formato e dados LASER para extrair contornos de telhados. O sistema desenvolvido inicialmente segmenta a imagem no espaço de cores CEILUV e filtra as regiões correspondentes à vegetação e a objetos baixos (estes são identificados através dos dados LASER). O último passo consiste em regularizar os contornos remanescentes da filtragem usando o algoritmo de Douglas-Peucker. Já em Cheng et al. (2008) os edifícios segmentados nos dados LASER são usados para isolar as regiões na imagem aérea que os contêm. Na sequência, as duas direções principais de cada edifício são determinadas nos dados LASER. As direções principais dos edifícios permitem realizar a detecção direcional de segmentos de retas. As retas remanescentes são agrupadas para gerar os contornos fechados dos edifícios. Awrangjeb et al. (2012) apresentam um método para reconstrução automática de telhados 3D através da integração de dados LASER com imagem multiespectral. As informações provenientes de ambos os dados são utilizadas para a classificação de retas detectadas na imagem entre terreno, árvore, contorno e cumeeira de telhado. Os pontos dos dados LASER considerados acima do terreno, próximos a retas longas de contornos de telhados, são utilizados para gerar planos de telhados iniciais e para selecionar as demais retas que compõem cada telhado de edifício. Em Chen et al. (2012) é proposto um método para detecção de edifícios com uso de dados LASER e imagem QuickBird. Os dados LASER são utilizados para gerar um MDSn (Modelo Digital de Superfície normalizado) e, assim serem 
obtidos os candidatos a representar edifícios, em seguida, a vegetação é filtrada com base em informações da imagem.

Com o objetivo de solucionar as dificuldades encontradas na extração automática de contornos e cumeeiras de telhados a partir de dados laser e de imagens aéreas de alta-resolução (pixels de $0,5 \mathrm{~m}$ ou menores), e tendo em vista que, a nuvem de pontos LASER permite extrair estes tipos de feições com relativa robustez, mas a qualidade geométrica desses resultados deixa a desejar, Dal Poz et al. (2009) propuseram uma metodologia para o refinamento geométrico de contornos de telhados previamente extraídos de dados de varredura a LASER, usando imagens aéreas de alta resolução e MRF. Primeiramente, os contornos 3D representando contornos de telhados são transformados para o espaço imagem através de técnicas fotogramétricas. Na sequência, as retas extraídas da imagem e as projetadas são utilizadas para estabelecer uma descrição MRF com base em relações (comprimento, orientação e proximidade) entre ambos os conjuntos de retas. A função de energia associada com a descrição MRF é minimizada através de uma versão modificada do algoritmo de força bruta, resultando num agrupamento de retas para cada contorno de telhado. Marcato (2010a) e Marcato e Dal Poz (2010) desenvolveram uma metodologia para selecionar automaticamente o detector de descontinuidades relacionadas com contornos e cumeeiras de telhados. Essa combinação de detectores é necessária porque em imagens aéreas de alta resolução os contornos e cumeeiras de telhados geralmente manifestam-se como bordas degrau e linhas, respectivamente. Também foram desenvolvidos algoritmos para a filtragem de retas pertencentes ao terreno com base em dados LASER 3D e para a redução de fragmentação de retas via regras de agrupamento perceptivo. Uma desvantagem do método é que retas sobre e muito próximas aos telhados não podem ser eliminadas. Marcato (2010b) integrou os desenvolvimentos realizados em Marcato (2010) na metodologia proposta em Dal Poz et al. (2009).

Assim, a presente pesquisa apresenta a continuidade do trabalho desenvolvido em Marcato (2010b). É proposto o aperfeiçoamento da função de energia, através da adição de novos critérios, tais como as injunções de retangularidade e quina, bem como a modelagem das estruturas de cumeeiras para dar maior robustez na descrição topológica da estrutura de telhado. Também é proposto o uso do Algoritmo Genético (AG) para otimizar a função de energia, uma vez que em casos envolvendo edifícios complexos, a utilização do método original tornava inviável computacionalmente, conforme Dal Poz et al. (2009).

\section{MÉTODO}

As principais etapas do método são o pré-processamento, o estabelecimento da função de energia $(\mathrm{U}(\mathrm{x}))$ com base em um modelo MRF, a minimização da função de energia através de um algoritmo de otimização e a complementação dos agrupamentos de retas obtidos para a geração de telhados completos. As subseções seguintes apresentam detalhes sobre cada etapa do método proposto. 


\subsection{Pré-Processamento}

O pré-processamento consiste da extração automática de segmentos de retas, na imagem, correspondentes a bordas e linhas de imagem, com heurísticas para filtrar parte das retas que não correspondem a contornos e cumeeiras de edifícios.

Inicialmente, as retas correspondentes a lados de contorno e cumeeiras de telhados de edifícios, previamente reconstruídos a partir de uma nuvem de pontos laser, são projetadas na imagem aérea. As retas projetadas são utilizadas para gerar janelas na imagem (subimagens), a fim de restringir o espaço de busca e facilitar a identificação de feições retas que correspondam a contornos e cumeeiras de telhados de edifícios nessa imagem. As janelas retangulares contendo as feições retas projetadas são geradas de tal forma que: 1) cada feição reta projetada é coincidente com o eixo de simetria da janela que a contém; 2) as dimensões das janelas são calculadas em função dos comprimentos e erros de registro das respectivas feições retas projetadas; e 3) o erro de registro é estimado através da lei de propagação de erros (GEMAEL, 1994) aplicada às equações de transformação dos vértices 3D para o espaço-imagem.

Para o processo de extração de retas imagem em cada uma dessas janelas geradas são utilizados dois detectores, o detector de bordas Canny (CANNY, 1986) e o detector linhas de Steger (STEGER, 2000). Isso porque, o problema de análise de imagem em questão é relativamente complexo, demandando cuidados com a escolha de operadores de bordas ou linhas para eficientemente extrair os contornos e cumeeiras de telhado. Esses cuidados decorrem do fato de que, geralmente, os contornos de telhados se manifestam geralmente como os perfis mais comuns encontrados em imagens, isto é, as descontinuidades do tipo degrau. Já as cumeeiras manifestam-se geralmente como linhas, assemelhando-se a duas bordas degraus bem próximas. Assim, deve-se identificar onde se deve reter o resultado do detector de bordas de Canny e onde se deve reter o resultado do detector de linhas de Steger (MARCATO, 2013).

Adicionalmente, são aplicadas técnicas para a eliminação de retas pertencentes ao terreno e para a redução da fragmentação dos segmentos de lados de contornos e cumeeiras. Para a eliminação de retas pertencentes ao terreno é necessário detectar quais as retas que pertencem ao terreno, associando a essas retas dois parâmetros: a altura média e o erro de registro médio. A altura média é obtida do modelo 3D de edifício a ser refinado e o erro de registro depende basicamente das precisões dos pontos laser e da matriz de variância-covariância dos parâmetros de orientação da imagem. Para facilitar a identificação das retas que pertencem ou não ao terreno, associa-se a cada pixel da imagem um valor de altura e outro de erro de registro. A determinação da altura em cada pixel da imagem é feita em dois passos: 1) transforma-se, via técnicas fotogramétricas convencionais, cada ponto LASER (P(X, Y, Z)) no seu correspondente ponto $(\mathrm{p}(\mathrm{L}, \mathrm{C}))$ no sistema digital da imagem; e 2) determina-se a altura $Z$ para cada pixel da imagem, via interpolação pelo vizinho mais próximo. Já a determinação do erro $\left(e_{\text {registro }}\right)$ de registro é realizada com base na lei de propagação de covariância, tendo por base a equação 
de tranformação do ponto $\mathrm{P}(\mathrm{X}, \mathrm{Y}, \mathrm{Z})$ no ponto $\mathrm{p}(\mathrm{L}, \mathrm{C})$, a matriz de variânciacovariância dos parâmetros de orientação exterior e as variâncias das coordenadas dos pontos LASER. O valor do erro de registro é obtido a partir das variâncias nas coordenadas L $\left(\sigma_{L}^{2}\right)$ e $\mathrm{C}\left(\sigma_{C}^{2}\right)$ do ponto projetado na imagem, utilizando a Equação 1. O erro de registro é obtido em cada pixel da imagem através do interpolador do vizinho mais próximo.

$$
e_{\text {registro }}=\sqrt{\sigma_{C}^{2}+\sigma_{L}^{2}}
$$

Com esses dois parâmetros calculados em cada pixel da imagem, são verificadas as retas com alturas compatíveis ao terreno, através da comparação da altura média da reta com a altura média do edifício, obtida do poliedro do edifício, e são eliminadas as que a distância média ao edifício forem maior que o erro de registro médio do local.

Para a redução da fragmentação de retas basta detectar e conectar as retas próximas e colineares, ou seja, com valores de distâncias e ângulos, calculados entre as retas, próximos de 0 (zero), possibilitando a redução da fragmentação das retas remanescentes. As retas pertencentes ao terreno devem ser eliminadas primeiro, uma vez que este procedimento possibilita reduzir o espaço de fusão e as possíveis falhas.

Na sequência, tendo em vista que o processo de detecção de retas na imagem é realizado individualmente para cada lado de contorno e cumeeira, são eliminadas as retas menores que $15 \%$ em relação a sua referência (reta de lado de contorno ou cumeeira $3 \mathrm{D}$ projetada) e as que diferem muito em orientação (tipicamente é adotado o valor limite de $20^{\circ}$ ).

$\mathrm{O}$ pré-processamento descrito acima permite gerar retas candidatas a representar lados de contorno e cumeeiras de telhado de edifício com um mínimo de fragmentação e falsas positivas. Como esse processo é aplicado individualmente para cada lado de contorno e cumeeira, ao final, sabe-se especificamente quais retas são candidatas a representar cada lado de contorno ou cumeeira.

\subsection{Conceitos de MRF e a Função de Energia}

\subsubsection{Conceitos Básicos de MRF}

O modelo MRF tem como grande vantagem caracterizar a informação contextual, ou seja, modelar relações espaciais entre primitivas (por exemplo, segmentos de retas, contorno, entre outras). Assim, sua aplicação em problemas como, por exemplo, agrupamento de retas para formar contorno e cumeeiras de telhados de edifícios é bastante interessante. Em um MRF, as primitivas $R=\left\{R_{1}\right.$, $\mathrm{R}_{2}, \ldots, \mathrm{R}_{n}$ \} estão relacionadas entre si de acordo com um sistema de vizinhança 
$\eta=\left\{\eta\left(R_{1}\right), \eta\left(R_{2}\right), \ldots, \eta\left(R_{n}\right)\right\}$, em que, $\eta\left(R_{i}\right), i=1,2, \ldots, n$, é o conjunto de todas as primitivas em $R$ vizinhas de $R_{i}$.

Seja $X=\left\{X_{1}, X_{2}, \ldots, X_{n}\right\}$ uma família de variáveis aleatórias definida sobre R, em que cada $X_{i}$ corresponde a $R_{i}$. Assim, $X$ é um MRF em $R$ com relação ao sistema de vizinhança $\eta$ se e somente se: $P[X=x]>0$ para todas as realizações de $X$; e $P\left[X_{i}=x_{i} \mid X_{j}=x_{j} \forall j \neq i\right]=P\left[X_{i}=x_{i}\left|X_{j}=x_{j} \forall j\right| R_{j} \in \eta\left(R_{i}\right)\right]$.

Nesse contexto, uma clique c é um subconjunto de primitivas de $\mathrm{R}$ tal que cada par de diferentes primitivas em c são vizinhas. O conjunto de todas as cliques de $\mathrm{R}$ com relação ao sistema de vizinhança $\eta$ é representado como $C(R, \eta)$.

Considerando que $\mathrm{X}$ tem um número finito de configurações em relação ao espaço amostral S, e que $P[X=x]>0$, dessa forma $X$ é um MRF, com respeito ao sistema de vizinhança $\eta$, somente se $X$ tem distribuição de probabilidade de Gibbs, conforme estabelece o teorema de Hammersley-Clifford (KOPPARAPU e DESAI, 2001) (Equação 2).

$$
P[X=x]=\frac{1}{Z} \exp ^{-U(x)}
$$

em que, $x$ é uma realização de $X$ e $Z$ é a constante de normalização, conforme pode ser visto na Equação 3 e U(x) é a função de energia de Gibbs (Equação 4).

$$
\begin{gathered}
Z=\sum_{\text {todaconf } . x} e^{-U(x)} \\
U(x)=\sum_{c \in C(R, \eta)} V_{c}\left(x^{c}\right)
\end{gathered}
$$

em que, $V_{c}\left(x^{c}\right)$ é a função potencial da clique e $x^{c}$ o valor das variáveis associadas com os nós pertencentes ao clique $c \in C(R, \eta)$. Maiores detalhes sobre a teoria de MRF pode ser vista em Kopparapu e Desai (2001).

\subsubsection{Função de Energia}

A função de energia utilizada nesse trabalho está associada a cinco termos de energia, dos quais três foram propostos em DAL POZ et al. (2009) e dois propostos nesse trabalho como aperfeiçoamento. A seguir os cinco termos de energia que compõem a função de energia são apresentados.

As feições retas extraídas com a detecção de retas na imagem que estão no entorno dos contornos de telhado projetado, são usadas para construir um modelo 
MRF expressando formas específicas de telhados de edifícios, com referência nos polígonos obtidos da projeção de contornos $3 \mathrm{D}$ de telhados. A função de energia é definida de forma que cada reta é associada com uma variável aleatória (xi), que assume valores binários de acordo com a regra especificada na expressão 5 (DAL POZ et al., 2009).

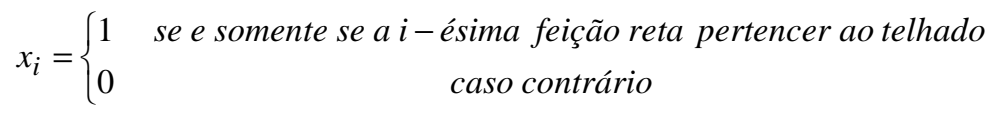

Essa regra (Expressão 5) dá origem a um vetor aleatório n-dimensional, em que n é o número de retas. Esse vetor randômico é a incógnita a ser determinada no processo de otimização.

A função de energia $\mathrm{U}(\mathrm{x})$ é formulada com base em cinco termos de energia. $\mathrm{O}$ primeiro termo $U_{1}(x)$ tem por finalidade favorecer retas longas com referência a reta projetada mais próxima (DAL POZ et al., 2009).

$$
U_{1}(x)=\sum_{i=1}^{n} x_{i} \frac{L_{F_{i}}^{L}}{L_{F_{i}}}
$$

em que, $L_{F_{i}}^{L}$ é o comprimento da reta projetada mais próxima da i-ésima reta extraída da imagem $\left(\mathrm{F}_{\mathrm{i}}\right) ; L_{F_{i}}$ é o comprimento da i-ésima reta extraída da imagem $\left(\mathrm{F}_{\mathrm{i}}\right)$.

O segundo termo da função de energia é chamado termo de proximidade e objetiva favorecer as retas mais próximas do contorno de telhado projetado.

$$
U_{2}(x)=\sum_{i=1}^{n} \sum_{j \mid j \in N_{i}} x_{i} \cdot x_{j} \cdot P(i, j)
$$

em que,

$$
P(i, j)=\frac{1}{2}\left(d_{i}^{1}+d_{i}^{2}+d_{j}^{1}+d_{j}^{2}\right)
$$

onde, $d_{i}^{1}$ e $d_{i}^{2}$ são as distâncias entre pontos extremos da reta $F_{\mathrm{i}}$ e a reta projetada mais próxima de $\mathrm{F}_{\mathrm{i}}$; e $d_{j}^{1}$ e $d_{j}^{2}$ são as distâncias entre pontos extremos da reta $F_{j}$ e a reta projetada mais próxima de $F_{j}$ (DAL POZ et al., 2009). 
O terceiro termo chama-se termo de orientação e tem por finalidade favorecer retas com orientações similares aos lados de contorno de telhado projetados.

$$
U_{3}(x)=\sum_{i=1}^{n} \sum_{j \mid j \in N_{i}} x_{i} \cdot x_{j} \cdot s_{\theta}(i, j)
$$

onde,

$$
s_{\theta}=\frac{2}{1+\exp \left[-\beta \cdot\left(\theta-\theta_{0}\right)^{2}\right]}-1
$$

em que, $\theta=\theta_{i}+\theta_{j}, \theta_{i}$ é o ângulo entre a reta $\mathrm{F}_{\mathrm{i}}$ e a reta projetada mais próxima dela; $\theta_{j}$ é o ângulo entre a reta $\mathrm{F}_{\mathrm{j}}$ e a reta projetada mais próxima dela, $\beta$ é uma constante positiva; $\theta_{0}$ é o valor ótimo $\left(0^{\circ}\right.$ ou $\left.180^{\circ}\right)$ do parâmetro $\theta$.

A injunção de retangularidade entra como o quarto termo na equação de energia e é dada pela Equação 11. Como os contornos de telhados são compostos por retas adjacentes aproximadamente ortogonais ou paralelas, o correspondente termo de energia pode ser expresso na forma,

$$
U_{4}(x)=\sum_{i=1 j|j|}^{n} \sum_{j \in N_{i}} x_{i} \cdot x_{j} \cdot\left|\operatorname{sen}\left(2 \alpha_{i j}\right)\right|
$$

em que, $\alpha_{i j}$ é o ângulo entre as retas $\mathrm{F}_{\mathrm{i}}$ e $\mathrm{F}_{\mathrm{j}}$.

Essa injunção trabalha com a comparação de par de retas extraídas da imagem, na verificação da ortogonalidade ou do paralelismo, isto é, $\operatorname{sen}\left(2 \times 0^{\circ}\right)=$ $\operatorname{sen}\left(2 \times 90^{\circ}\right)=0$.

A injunção de quina deve beneficiar pares de retas que se interceptam mais proximamente de quinas em $90^{\circ}$. Esse princípio pode ser matematicamente representado na forma,

$$
\mathrm{U}_{5}(\mathrm{x})=\sum_{\mathrm{i}=1 \mathrm{j} j \mathrm{j} \in \mathrm{N}_{\mathrm{i}}} \mathrm{x}_{\mathrm{i}} \cdot \mathrm{x}_{\mathrm{j}} \cdot \mathrm{D}_{\mathrm{ij}} \cdot \cos \left(\lambda_{\mathrm{ij}}\right)
$$

em que, $D_{i j}$ é a distância entre o ponto de intersecção entre as retas $F_{i}$ e $F_{j}$ e a quina $\left(\mathrm{q}_{\mathrm{ij}}\right)$ mais próxima detectada na imagem e $\lambda_{\mathrm{ij}}$ é o ângulo entre as bordas incidentes na quina $\mathrm{q}_{\mathrm{ij}}$. A detecção de quinas na imagem é feita pelo detector de Harris 
(HARRIS e STEPHENS, 1988), com o uso da biblioteca de classes C/C++ Halcon da MVTec.

Por fim, a equação de energia é formulada como,

$$
U(x)=\alpha_{1} \cdot U_{1}(x)+\alpha_{2} \cdot U_{2}(x)+\alpha_{3} \cdot U_{3}(x)+\alpha_{4} \cdot U_{4}(x)+\alpha_{5} \cdot U_{5}(x)
$$

em que, $\alpha_{1}, \alpha_{2}, \alpha_{3}, \alpha_{4}$ e $\alpha_{5}$ são constantes positivas e a soma delas é igual a 1 . Essas constantes são pesos que dão a importância relativa para cada termo da função de energia.

\subsection{Otimização da Função de Energia Usando AG}

Os AGs trabalham com um conjunto de soluções submetido ao princípio da sobrevivência dos indivíduos mais aptos para, dessa forma, encontrar uma solução cada vez melhor. Esses algoritmos aplicam aos indivíduos da população operadores naturais tais como a seleção dos melhores, o cruzamento entre eles e a mutação (GOLDBERG, 1989).

A estrutura de um AG é composta pela inicialização de uma população. E cada iteração do algoritmo genético corresponde à aplicação de um conjunto de operações básicas: cálculo de aptidão, seleção e reprodução (aplicação dos operadores genéticos). Maiores detalhes sobre os operadores genéticos pode ser vistos em Goldberg (1989).

A estrutura básica do algoritmo genético é mostrada na Figura 1:

Figura 1 - Estrutura Básica de um AG.

Fonte: Adaptado de Goldberg (1989).

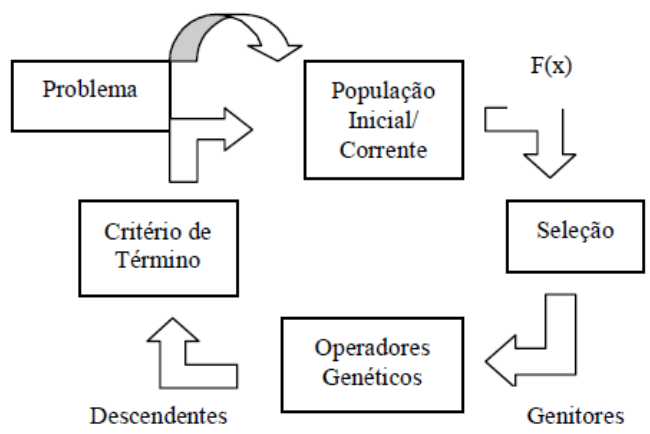

A estrutura de um AG é composta pela inicialização de uma população. Essa população de $\mathrm{n}$ indivíduos é gerada aleatoriamente. Cada um dos indivíduos da população representa uma possível solução para o problema, ou seja, um ponto no espaço de soluções. E cada iteração do algoritmo genético corresponde à aplicação 
de um conjunto de operações básicas: cálculo de aptidão, seleção e reprodução (aplicação dos operadores genéticos) (GOLDBERG, 1989).

Nesse trabalho, conforme mostrado, o vetor incógnito a ser determinado no processo de otimização é aleatório e binário. Assim, o problema já encontra-se concebido de forma a facilitar o uso do algoritmo AG para otimizar a função de energia.

O primeiro passo para aplicar esse método de otimização, consiste em inicializar a população. Nessa etapa, deve-se considerar a heurística de unicidade, ou seja, cada lado de contorno e cumeeira possui uma única correspondência. Para um melhor entendimento, de como é gerada a população inicial, é apresentado um exemplo ilustrativo de um telhado de edifício (Figura 2) e, na sequência (Figura 3) exemplos de indivíduos, que compõem a população inicial, gerados para a situação apresentada na Figura 2.

Figura 2 - Exemplo hipotético de um telhado. (a) Ilustração de um telhado; (b) retas extraídas da imagem.

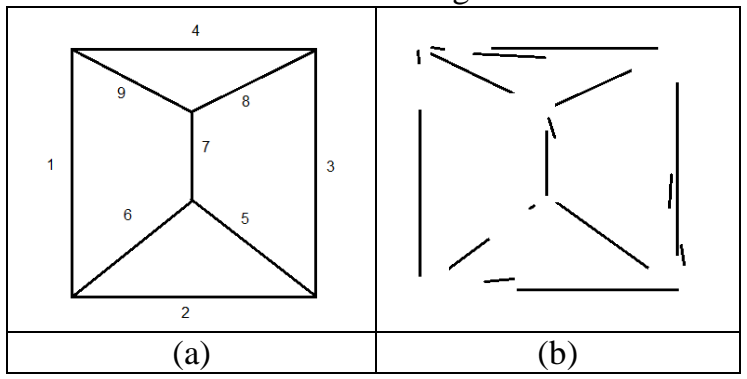

Na Figura 2(a) tem-se a ilustração de uma situação hipotética de um telhado de edifício que é composto por quatro lados de contorno e cinco cumeeiras. A Figura 2(b) ilustra o resultado obtido a partir do pré-processamento, ou seja, as retas candidatas a representar cada lado de contorno e cumeeira que foram extraídas da imagem. Como pode ser observado (Figura 2(b)), alguns lados de contorno e cumeeiras possuem mais de uma reta candidata. Tem-se que os lados de contorno 1 e 2 e as cumeeiras 6 e 7 possuem duas retas candidatas, os lados de contorno 3 e 4 possuem três retas candidatas e as cumeeiras 5, 8 e 9 apenas uma candidata.

A população inicial de $\mathrm{n}$ indivíduos é gerada atendendo a heurística de unicidade e para cada indivíduo da população a reta candidata a representar cada lado de contorno e cumeeira é selecionada aleatoriamente. Por exemplo, na Figura 3 , tem-se vetores binários $(1,2, \ldots, \mathrm{n})$ (cromossomos), em que cada célula (gene) representa uma reta candidata. Se determinada reta candidata a representar um lado de contorno ou cumeeira for selecionada, a variável aleatória associada com essa reta (gene) recebe o valor 1 e as demais retas candidatas aquele lado de contorno ou cumeeira recebe o valor 0 . Assim, cada cromossomo dessa população inicial possui 
uma configuração de retas representativas de lados de contornos e cumeeiras a ser testada.

No problema em questão, sempre é considerado que a reta correta está entre as candidatas e no caso de lados de contornos e cumeeiras não possuírem candidatas, as retas projetadas correspondentes são integradas ao processo.

Figura 3 - População inicial.

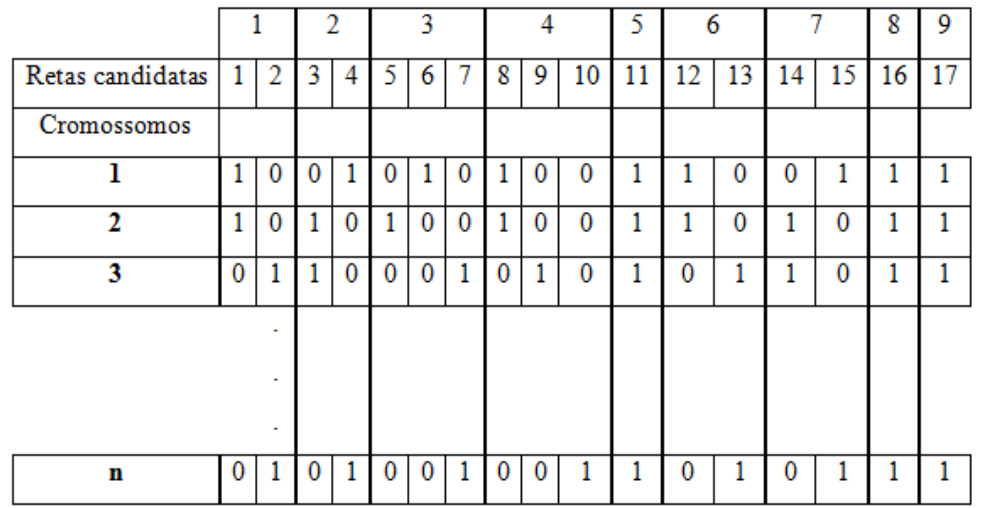

Gerada a população inicial, em seguida, é calculada a aptidão de cada cromossomo da população com o uso da função de energia (Equação 13). A seleção dos cromossomos tem por base o retorno da função de energia. Nesse trabalho utiliza-se a seleção por amostragem determinística (GOLDBERG, 1989). A técnica de reprodução utilizada é a troca de toda população por elitismo, ou seja, todos os indivíduos são considerados no processo de seleção. Isto é o indivíduo mais apto é copiado na população seguinte e $\mathrm{n}$ - 1 indivíduos são substituídos, com o uso dos operadores genéticos (cruzamento e mutação).

Com os indivíduos selecionados é iniciado o processo de cruzamento. Essa operação consiste em formar duplas de cromossomos de forma aleatória e com uma determinada probabilidade efetuar a troca de genes entre esses dois, a partir de um ponto de corte. Considerando ainda a heurística de unicidade, o ponto de corte selecionado de forma aleatória deve corresponder a um dos lados de contorno ou cumeeiras. Assim, são formados a partir de dois indivíduos outros dois novos. Um dos dois novos indivíduos possui os genes do primeiro indivíduo do ponto de corte para trás e os genes do segundo indivíduo do ponto de corte para frente. E outro novo indivíduo possui os genes do primeiro indivíduo do ponto de corte para frente e os genes do segundo indivíduo do ponto de corte para trás. O cruzamento, como já foi dito, tem uma probabilidade de acontecer, desse modo é possível não ocorrer o cruzamento entre uma determinada dupla e, assim, os indivíduos dessa dupla permanecerem os mesmos. 
Aplicado cruzamento, há a possibilidade de ocorrer a mutação em um determinado indivíduo. Na mutação, também deve ser considerada a heurística de unicidade. O ponto de mutação é selecionado aleatoriamente, da mesma maneira que o ponto de corte e é realizada a mutação por inversão. A mutação é realizada com uma determinada probabilidade de mutação, normalmente bastante baixa.

É realizado, em seguida, o cálculo da aptidão de cada cromossomo dessa nova população e é realizado todo o procedimento novamente. Esse processo repete-se até que se atinja um critério de parada pré-estabelecido. Nesse trabalho utiliza-se um valor limite de iterações para término do processo. O resultado consiste no indivíduo que ao final possuir a maior aptidão, ou seja, a configuração de retas selecionadas é estabelecida pelo cromossomo mais apto encontrado durante o processo de otimização por AG.

\subsection{Complementação dos Agrupamentos de Retas}

$\mathrm{O}$ método de otimização gera para cada telhado de edifício um agrupamento de retas. Essas retas, normalmente, apresentam-se desconexas, conforme pode-se observar no exemplo ilustrativo na Figura 4 (a). Para realizar a complementação do agrupamento de retas é necessário utilizar a topologia do correspondente polígono projetado (por exemplo, polígono azul na Figura 4 (b)) para selecionar as retas adjacentes.

Figura 4 - Ilustração da estratégia de complementação. (a) agrupamento das retas resultantes da otimização; (b) poliedro 3D de telhado projetado e agrupamento das retas resultantes da otimização; e (c) polígono representando o telhado refinado.

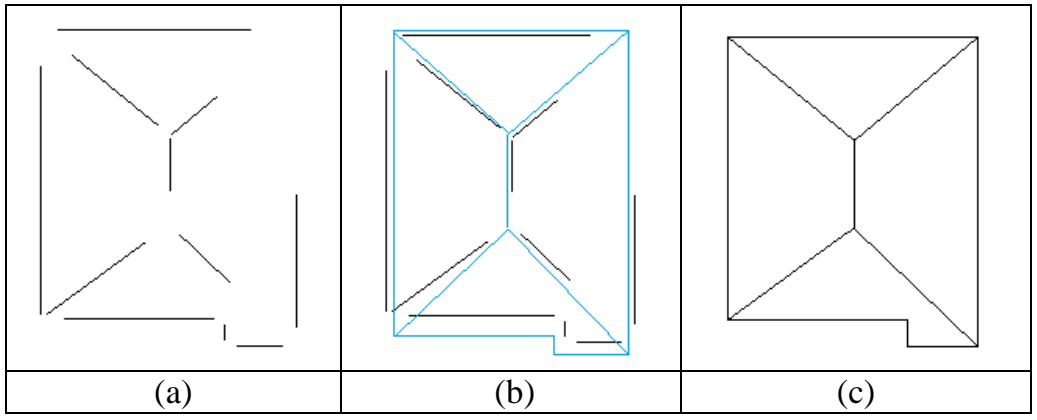

O exemplo de telhado de edifício apresentado na Figura 4 ilustra duas situações possíveis com relação ao número de retas que se encontram em um único vértice do telhado. No caso mais simples, em que se deve complementar o espaço entre duas retas, basta determinar o vértice do polígono através da intersecção de retas. Já quando o problema envolve determinar um ponto comum a três retas é 
realizado o ajuste de um ponto as três retas com o uso do método paramétrico de ajustamento (GEMAEL, 1994).

\section{RESULTADOS EXPERIMENTAIS}

Os dados utilizados na execução desse trabalho foram: Poliedros representando telhados de edifícios; uma imagem aérea digital (com parâmetros de orientação interior e exterior), de dimensões 4500 x 3000 pixels e resolução espacial de $20 \mathrm{~cm}$, da mesma área; e nuvem de pontos LASER com densidade de 2 pontos/ $\mathrm{m}^{2}$. Toda a parte de implementação computacional foi realizada em linguagem de programação $\mathrm{C} / \mathrm{C}++$.

A seguir são apresentados os valores estabelecidos para os limiares e parâmetros utilizados nesse trabalho.

- Precisão dos pontos LASER: altimetria $15 \mathrm{~cm}$ e planimetria $48 \mathrm{~cm}$;

- Tolerâncias para fusão de retas colineares e próximas $\theta=9^{\circ}$ e $d=3$ pixels;

- Constante para controlar a forma da função sigmoide $\beta=20$; e

- Pesos $\alpha_{1}=\alpha_{2}=\alpha_{3}=\alpha_{4}=\alpha_{5}=0,2$. Nesse trabalho, foram considerados pesos iguais para todos os termos de energia.

- Probabilidade de cruzamento, $\mathrm{pc}=0,7$, e mutação, $\mathrm{pm}=0,01$.

Vale lembrar que esses parâmetros e limiares foram mantidos iguais para todos os experimentos.

Também foram estabelecidos parâmetros relacionados a tamanho da população gerada aleatoriamente para inicialização do AG e número de gerações (iterações) como critério de parada do método de otimização. A escolha desses valores dependeu fundamentalmente da quantidade de retas projetadas que compõem o telhado de edifício a ser testado, bem como, da quantidade de retas candidatas extraídas da imagem. Esses valores são específicos para cada experimento e serão apresentados junto aos resultados.

A Figura 5 (a) apresenta a projeção do primeiro poliedro 3D de telhado em uma subimagem que contém o primeiro edifício teste. Pode-se observar que a projeção não foi acurada para praticamente todos lados de contorno e cumeeiras. Além disso, próximo a reta 5 o telhado de edifício possui detalhes não representados. Na Figura 5 (b) estão sobrepostas dezoito retas extraídas da imagem através das técnicas de pré-processamento propostas. Os lados de contorno 1, 2, $3 \mathrm{e}$ 6 e a cumeeira 9 possuem um reta candidata, os lados de contorno 4 e 5 e as cumeeiras 7,8 e 10 possuem duas retas candidatas e a cumeeira 11 possui três retas candidatas. Destaca-se, nesse experimento a dificuldade de se extrair retas completas nessa imagem.

Nesse experimento, foram gerados aleatoriamente quinze $(n=15)$ cromossomos para a inicialização do AG, também, foi considerado como critério de parada o valor igual 20 gerações. As retas selecionadas, via método de otimização AG, como pertencentes ao telhado do edifício podem ser observadas na Figura 5 (c). 
Nota-se que a única falha encontrada está relacionada à reta projetada 5. Essa reta apresentava duas candidatas a sua substituição, conforme dito anteriormente, sendo que uma delas representava de forma fiel o lado de contorno em questão. No entanto, no processo de otimização a reta mantida não é a correta. Sendo assim, esse telhado de edifício é composto por onze retas das quais dez estão corretas $(91 \%)$ e uma (9\%) está incorreta (falsa positiva). Essa falha pode ser justificada através de dois motivos: 1) o pré-processamento falhou na eliminação da reta que parece pertencer ao terreno; e 2) devido aos erros na geração do modelo $3 \mathrm{D}$ a reta que melhor atende as condições impostas pela função de energia é a incorreta.

Figura 5 - Edifício teste 1. (a) telhado projetado; (b) retas extraídas da imagem; (c) resultado da otimização; e (d) resultado após aplicação das regras de complementação.

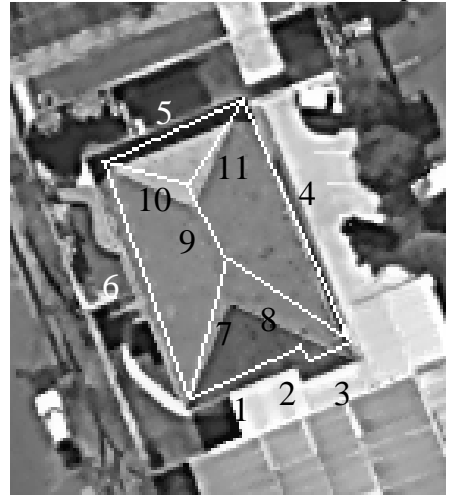

(a)

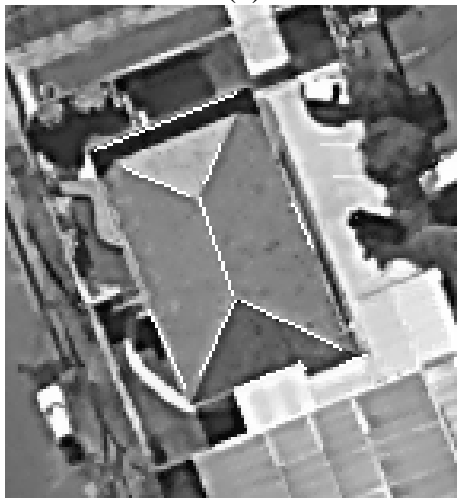

(c)

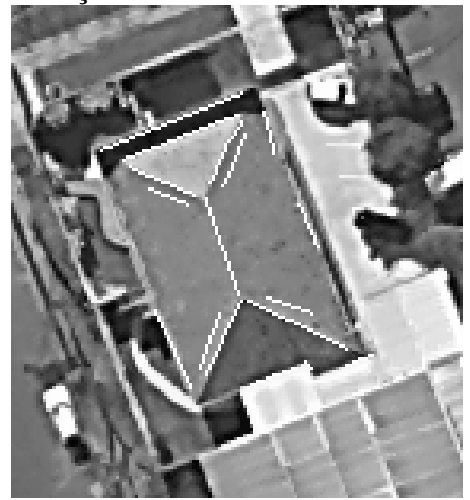

(b)

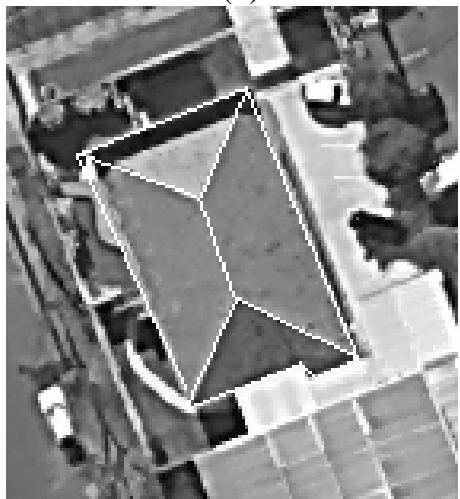

(d)

Quando se trata dos termos de energia de orientação e retangularidade ambas as retas respondem de forma similar, no entanto, para os termos de comprimento, 
proximidade e quina a reta incorreta é favorecida. A injunção de quina favoreceu a reta incorreta, pois dentre as quinas detectadas na imagem, justamente pelo fato dos vértices do telhado para esse lado de contorno não serem representados por apenas uma quina (presença de detalhes omitidos pelo polígono projetado), não existia uma quina que favorecia o agrupamento da reta correta, ao contrário da situação para a reta incorreta.

Na Figura 5 (d) é apresentado o resultado obtido com a complementação do agrupamento de retas. Todas as onze retas foram substituídas pelas correspondentes retas selecionadas via otimização da função de energia. Assim, para esse procedimento foi necessário somente usar a topologia do polígono projetado. Os

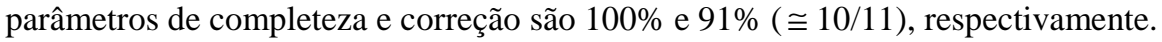

A Figura 6 mostra o segundo edifício teste utilizado. Na Figura 6 (a) o poliedro 3D do telhado do edifício está sobreposto na imagem. Nota-se que, o polígono resultante tem um deslocamento bastante acentuado para a direita.

Para esse telhado de edifício foram extraídas da imagem dezoito retas. Sua distribuição ao redor do telhado projetado é a seguinte: todos os quatro lados de contorno possuem duas retas candidatas, duas cumeeiras possuem uma reta candidata, outras duas cumeeiras possuem duas retas candidatas e uma cumeeira possui quatro retas candidatas (Figura 6(b)).

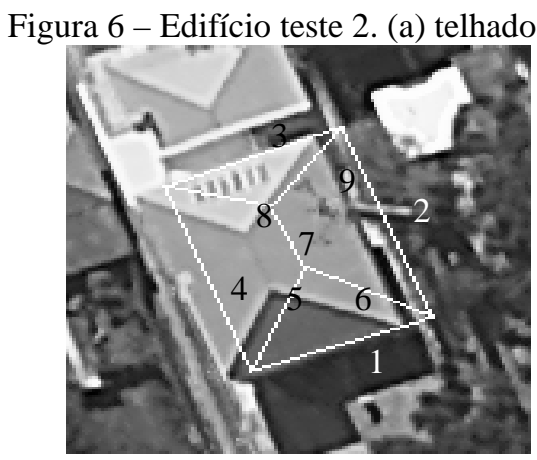

(a)

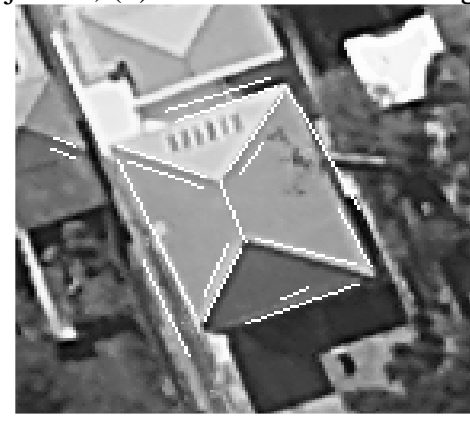

(b)

De modo semelhante ao experimento anterior, o tamanho da população inicial do AG é igual quinze $(\mathrm{n}=15)$ e o número de gerações é igual a 20 .

A Figura 7 (a) apresenta o resultado obtido no processo de otimização. Notase que a função de energia proposta combinada com o método de otimização AG apresentou um bom resultado, uma vez que dentre as retas candidatas optou pelas que melhor representavam o telhado de edifício. Sendo assim, esse telhado de edifício é composto por nove retas das quais todas estão corretas (100\%).

Na Figura 7 (b) é apresentado o resultado obtido com a complementação do agrupamento de retas. Todas as nove retas foram substituídas pelas correspondentes 
retas selecionadas via otimização da função de energia. Assim, para esse procedimento foi necessário somente usar a topologia do polígono projetado. Os parâmetros de correção e completeza são $100 \%$ e $100 \%$, respectivamente, que mostra a excelente qualidade geométrica do polígono que representa o telhado do edifício refinado.

Figura 7 - Edifício teste 2. (a) resultado da otimização da função de energia; e (b) resultado após aplicação das regras de complementação.

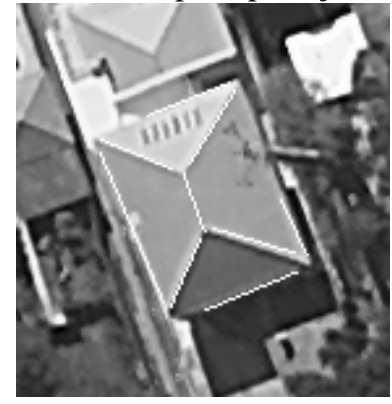

(a)

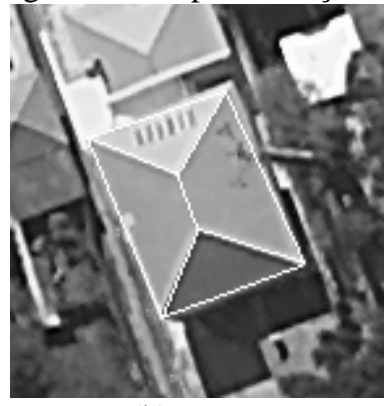

(b)

O próximo edifício teste possui a forma de um ' $E$ ' invertido e é definido por dezenove retas de contorno e vinte retas de cumeeiras. A Figura 8 (a) mostra os lados de contorno e cumeeiras de telhado 3D projetado e sobreposto na imagem. De um modo geral, o polígono resultante está relativamente próximo aos lados de contorno e cumeeiras do telhado de edifício, uma vez que o erro de registro máximo é de cerca de 5 pixels. O maior erro de registro pode ser observado na reta 5 do polígono. Também, pode-se observar que as retas 13 e 15 não representam corretamente os detalhes do telhado e há uma pequena falha, no poliedro $3 \mathrm{D}$ gerado, próxima as cumeeiras $20,23,38$ e 39, nesse caso, também, o detalhe no telhado do edifício não foi representado.

Na Figura 8 (b) estão sobrepostas trinta e nove retas extraídas da imagem através das técnicas de pré-processamento. Sua distribuição em torno do telhado projetado é a seguinte: trinta e uma retas projetadas possuem apenas uma reta candidata, quatro retas projetadas possuem duas retas candidatas e quatro retas projetadas não possuem candidatas. Ainda nessa figura, deve-se destacar que as retas projetadas representando os lados de contorno 11, 13, 15 e 17 não apresentaram candidatas e por esse motivo, como previsto no método, na falta de retas candidatas, a própria reta projetada é considerada no processo de otimização.

Nesse experimento, o tamanho da população inicial gerada aleatoriamente pelo o processo de otimização AG é igual a 25 e o número de gerações igual a 40 . As retas selecionadas como lados de contorno e cumeeiras podem ser observadas na Figura 8 (c). O método proposto identificou $34(87,2 \%)$ retas corretas, uma $(2,6 \%)$ incorreta (falsa positiva) e quatro $(10,2 \%)$ não possuíam correspondência (falsas 
negativas). A reta incorreta está relacionada com a presença de somente de uma candidata inválida. A Figura 8 (d) mostra o resultado obtido com a aplicação da técnica de complementação do agrupamento de retas. Trinta e cinco retas de lados de contorno e cumeeiras de telhado projetado foram substituídas pelas correspondentes retas selecionadas via otimização da função de energia. As retas projetadas $11,13,15$ e 17 foram mantidas devido a ausência de candidatas entre as retas extraídas pelas técnicas de pré-processamento.

Figura 8 - Edifício teste 3. (a) telhado projetado; (b) retas extraídas da imagem; (c) resultado da otimização; e (d) resultado após aplicação das regras de complementação.

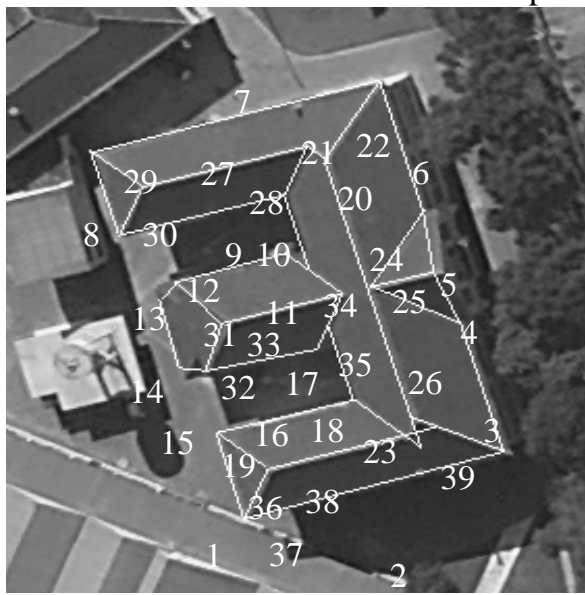

(a)

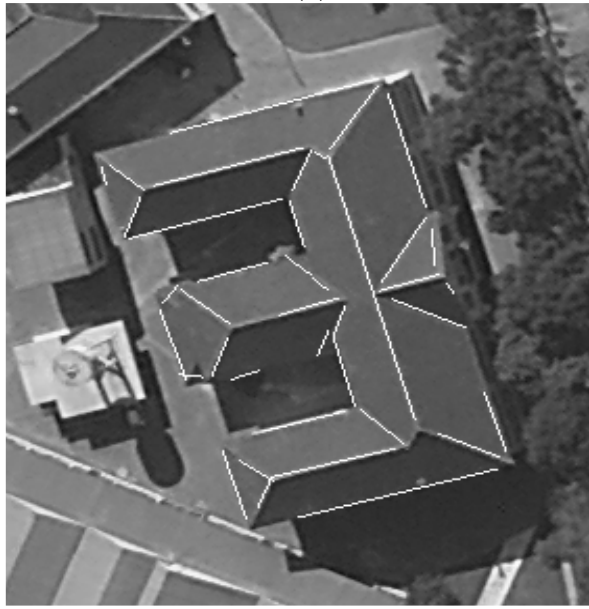

(c)

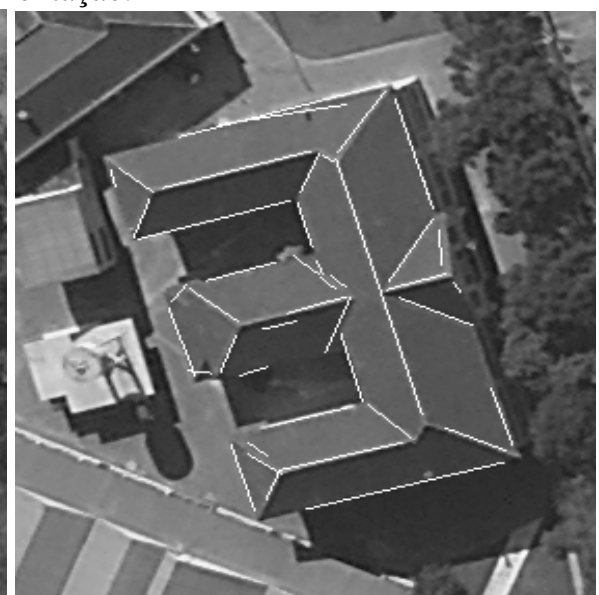

(b)

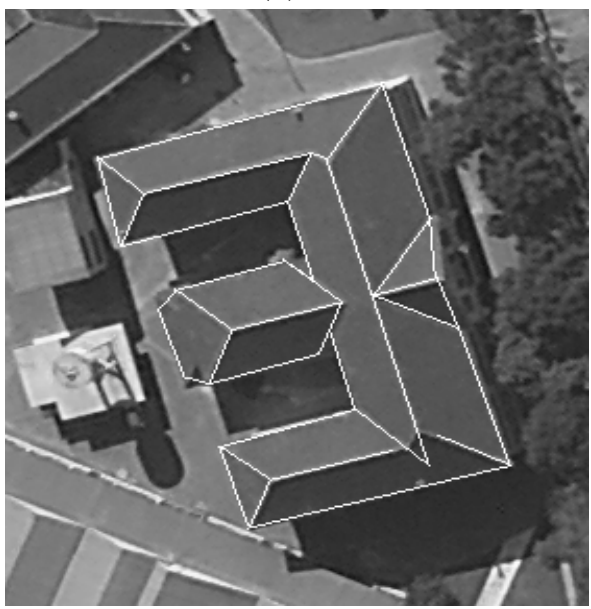

(d)

Bol. Ciênc. Geod., sec. Artigos, Curitiba, v. 20, nº 3, p.647-668, jul-set, 2014. 
O método proposto não foi capaz de fornecer resultados satisfatórios ao longo de três lados de contorno do polígono refinado. Isso devido a ausência de candidata válida para a reta projetada 5 e, também, pela pobre descrição dos detalhes do telhado 3D ao longo dos lados 13 e 15. Observa-se, também, que houve um problema na complementação do agrupamento de retas próximo as cumeeiras 20 , 23, 38 e 39, isso porque nesse local, conforme dito anteriormente, houve uma falha no processo de geração do poliedro 3D do telhado. Nesse sentido, tendo por base a

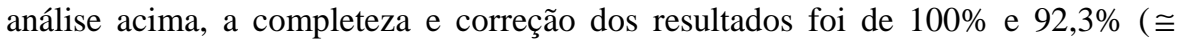
$36 / 39$ ), respectivamente.

\section{CONCLUSÃO}

Nesse trabalho foi proposto um método para reconstruir contornos e cumeeiras de telhados de edifícios a partir de imagens aéreas de alta-resolução e poliedros representativos de edifícios extraídos de dados LASER. Nesse método buscou-se refinar geometricamente os telhados 3D extraídos dos dados de varredura a LASER com o uso de uma imagem aérea de alta-resolução.

Para a avaliação do método proposto foram realizados experimentos com diferentes edifícios. Os resultados obtidos foram satisfatórios. Esse método foi capaz de fornecer polígonos de telhado de edifícios refinados em que a maioria de seus lados de contorno e cumeeira foram geometricamente melhorados.

Como já foi mencionado anteriormente, esse trabalho propôs melhorias em uma metodologia preexistente. As principais modificações nessa metodologia foram: inclusão de dois novos termos de energia (injunção de retangularidade e quina) na função de energia, integração da estrutura de cumeeira e o uso do algoritmo genético como método de otimização.

A inclusão das injunções de retangularidade e quina, teve por objetivo contribuir para melhores resultados para o contorno do telhado do edifício. O uso desses dois termos de energia permitiu integrar ao processo uma perspectiva de contexto. Anteriormente, os três termos de energia dependiam fundamentalmente das retas projetadas de referência. Esse aspecto é bastante interessante, pois como visto, alguns poliedros 3D de telhados extraídos de dados de varredura a LASER não apresentam bons resultados para alguns de seus lados.

A integração da estrutura de cumeeira, também, contribuiu positivamente no processo. Sabe-se que as cumeeiras sofrem menos com as interferências externas e, dessa forma, tem uma detecção na imagem mais clara e limpa e em sua maioria corretas.

O uso do algoritmo genético como método de otimização proporcionou bons resultados. Em todos os experimentos realizados não foram constatadas falhas produzidas por esse método. Deve-se destacar que a implementação do AG foi bastante simples, o método é rápido e os resultados obtidos corresponderam à expectativa. Esse método, também, possui uma vantagem básica em relação ao método de força bruta, que é o tratamento de casos com alta dimensionalidade, caso do edifício em ' $\mathrm{E}$ ' invertido. 
Para trabalhos futuros, recomenda-se refinar a função de energia com conhecimentos relacionados a cor, sombras, entre outros, o que pode melhorá-la e adaptar o algoritmo genético para lidar com situações em que a candidata correta não está entre as candidatas. Recomenda-se, também, realizar mais experimentos com telhados de edifícios de maior complexidade e utilizar os resultados obtidos para refinar o poliedro LASER. Por fim, recomenda-se realizar testes com poliedros gerados com dados de varredura a LASER de diferentes densidades. Espera-se que esse método seja mais útil para poliedros gerados a partir de densidades baixas.

\section{AGRADECIMENTOS:}

Os autores gostariam de agradecer à FAPESP (Fundação de Amparo à Pesquisa do Estado de São Paulo) pelo financiamento dessa pesquisa através de uma bolsa de mestrado (Processo no 2011/03899-9).

\section{REFERÊNCIAS BIBLIOGRÁFICAS}

AWRANGJEB, M.; ZHANG, C. FRASER, C. S. Automatic reconstruction of building roofs through effective integration of Lidar and multispectral imagery. In: XXII ISPRS Congress, 2012, Melbourne. Proceedings v. I-3, Melbourne, 2012.

BOTELHO, F. M.; CENTENO, J. A. S. Reconstrução tridimensional de edificações utilizando dados laser scanner aerotransportados. Boletim de Ciências Geodésicas, v. 13, n. 1, p. 107-126, 2007.

CANNY, J. A Computational Approach to Edge Detection. IEEE Transactions on Pattern Analysis and Machine Intelligence, v. 8, n. 6, p. 679-698, 1986.

CHENG, L.; GONG, J.; CHEN, X.; HAN, P. Building boundary extraction from high resolution imagery and LIDAR data. The International Archives of the Photogrammetry, Remote Sensing and Spatial Information Sciences, v. 37, p. 693-698, 2008.

CHEN, L.; ZHAO, S., HAN, W.; LI, H. Building detection in an urban area using lidar data and QuickBird imagery. International Journal of Remote Sensing, v.33, p. 5135-5148, 2012.

DAL POZ, A. P.; FAZAN, A. J.; CORREIA, L. S.; MARCATO, V. J. Automated building extraction: comparison of paradigms and examples. In: $6^{\text {th }}$ International Symposium on Mobile Mapping Technology, Presidente Prudente. Proceedings of 6th ISMMT, 2009a.

DAL POZ, A. P.; HABIB, A. F.; MARCATO, V. J.; CORREIA, L. S. Uso de dados fotogramétricos no refinamento geométrico de contornos de telhados de edifícios extraídos de dados LASER. Boletim de Ciências Geodésicas, v.15, n. 4, p. $594-614,2009$.

GALVANIN, E. A. S.; DAL POZ, A. P. Extraction of building roof countors from Lidar using a Markov-Random-Field-Based approach. IEEE Transactions Geocience and Remote Sensing, v.50, p. 981-987, 2012. 
GEMAEL, C. Introdução ao Ajustamento de Observações: Aplicações Geodésicas. Universidade Federal do Paraná, Curitiba, 1994.

GOLDBERG, D. E. Genetic Algorithms in Search, Optimization, and Machine Learning. Addison-Wesley, Reading, MA, 1989.

HAALA, N.; BRENNER, C. Extraction of buildings and trees in urban environments. ISPRS Journal of Photogrammetry and Remote Sensing, v.54, p. 130-137, 1999.

HARRIS, C.; STEPHENS, M. A combined corner and edge detector. In: Fourth Alvey Vision Conferece, University of Manchester, Proceedings, p. 147-151, 1988.

LAFARGE, F.; DESCOMBES, X.; ZERUBIA, J.; PIERROT-DESEILLIGNY, M. Automatic building extraction from DEMs usisng an object approach and application to the 3D-city modeling. ISPRS Journal of Photogrammetry and Remote Sensing, v. 63, p. 365-381, 2008.

MACHADO, A. M. L.; MITISHITA, E. A. Detecção automática de contornos de edificações utilizando imagem gerada por câmera digital de pequeno formato e dados LIDAR. Boletim de Ciências Geodésicas, v. 12, n. 3, p. 215-233, 2006.

MARCATO, V. J. Seleção automática dos métodos de Canny e Steger para a detecção acurada e confiável de linhas e bordas associadas com contornos e cumeeiras de edifícios. Presidente Prudente, 2010a. Relatório de iniciação científica (FAPESP), Curso de Graduação em Engenharia Cartográfica, Faculdade de Ciências e Tecnologia, Universidade Estadual Paulista.

MARCATO, V. J. Seleção automática dos métodos de Canny e Steger para a detecção acurada e confiável de linhas e bordas associadas com contornos e cumeeiras de edifícios. Presidente Prudente, 2010b. Relatório de iniciação científica (FAPESP), Curso de Graduação em Engenharia Cartográfica, Faculdade de Ciências e Tecnologia, Universidade Estadual Paulista.

MARCATO, V.J. Reconstrução de contornos e cumeeiras de telhados de edifícios a partir de imagens aéreas de alta-resolução e poliedros representativos de edifícios extraídos de dados LASER. Presidente Prudente, 2013. Dissertação (mestrado) - Curso de Pós-Graduação em Ciências Cartográficas, FCT/UNESP.

MARCATO, V. J.; DAL POZ, A. P. Metodologia híbrida para a extração de segmentos de contornos e cumeeiras de telhados de edifícios em imagens aéreas de alta resolução. In: VI Workshop de Visão Computacional, Presidente Prudente, São Paulo. Anais... 2010.

ROTTENSTEINER, F.; TRINDER, J.; CLODE, S.; KUBIK, K. Automated delineation of roof planes from LIDAR data. In: International Archives of the Photogrammetry, Remote Sensing and Spatial Information Sciences, Enschede, The Netherlands. Proceedings... 2005.

SOHN, G. Extraction of buildings from high-resolution satellite data and lidar. In: XX ISPRS CONGRESS, 2004, Istanbul, Turkey. Proceedings... 2004. 
SOHN, G.; DOWMAN, I. J. Building extraction using Lidar DEMs and Ikonos images. In: The International Archives of the Photogrammetry, Remote Sensing and Spatial Information Sciences, Dresden, Germany, v. 34. Proceedings... 2003.

STEGER, C. Subpixel - Precise Extraction of Lines and Edges. International Archives of the Photogrammetry, Remote Sensing, v. 33, Amsterdam. Proceedings... 2000.

VOSSELMAN, G. Building reconstruction using planar faces in very high density height data. In: The International Archives of the Photogrammetry, Remote Sensing and Spatial Information Sciences, La Jolla, USA. Proceedings... 1999, p. 87-92.

(Recebido em setembro de 2013. Aceito em abril de 2014). 